\title{
Histochemical Study in the Adrenal Cortex in Patients Associated with Hypertension
}

\author{
Hideo Tsuchiyama \\ Department of Pathology, Nagasaki University Shool of Medicine
}

A study of the autopsy cases associated with hypertension has shown a tendency of adrenal cortical hyperplasia. ${ }^{1,7,8)}$ However, detail of histochemical findings in such cases has not been fully reported. In this paper histochemical observations on the adrenal hyperplasia and adenoma in hypertensive patients are recorded.

\section{Materials and Methods}

Fresh adrenal glands procured from 32 autopsy cases associated with hypertension were examined. These materials consist of 2 cases of primary aldosteronism with adenomas, 21 cases of severe renal disease and 9 cases of socalled essential hypertension. Many adrenals showed hyperplasia or adenoma in various grade. As control 10 cases dying of accidental trauma without acute or chronic disease were used. Tissues were placed in Baker's calcium-formalin, Telleysniczky's solution and 10 per cent buffered formalin. Multiple frozen, carbowax or paraffin sections, 3 to $15 \mu$ in thickness were cut from each gland. These sections were stained as follows: (1) Sudan III stain for the general lipids: (2) Schultz's reaction for cholesterol and similar sterols: (3) SmithDietrich's stain for phospholipid and other lipoid; (4) Ponceau-fuchsin stain for ketosteroid-protein complex and (5) Neotetrazorium salt reaction for the reducing activity of corticosteroids. Detail of these methods from (1) to (4) have been discussed elsewhwere. ${ }^{5,9}$ The technic of last one will be interpreted as follows: (a) The tissue slice was fixed in 10 per cent neutral formaldehyde solution for several hours, (b) washed in running water for several hours. (c) frozen sections were placed in $0.5 \mathrm{~N}$ sodium hydroxide for 15 minutes, (d) incubated for 1 hour at $50^{\circ} \mathrm{C}$ in 10 per cent freshly prepared sodium thioglycolate, adjusted to $\mathrm{PH} 8.0$ with $0.1 \mathrm{~N}$ sodium hydroxide just before use, (e) then incubated for 20 hours at $37^{\circ} \mathrm{C}$ in freshly prepared $0.1 \mathrm{M}$ iodoacetic acid, adjusted to $\mathrm{pH} 8.0$ with $0.1 \mathrm{~N}$ sodium hydroxide just before use, (f) stained with a solution prepared from equal volumes of 1.0 per cent neotetrazorium solution and $1 \mathrm{~N}$ sodium hydroxide for 10 minutes. Positive reaction was demonstrated with fine reddish granules. ${ }^{3)}$

\section{Results}

An increase in width of the zona glomerulosa was noted in half of the cases of hypertensive patients. In sections stained with sudan III, a fairly various quantity of lipids was found in the zona glomerulosa. Small to middle- 
sized droplets of lipid were distributed throughout this zone in 13 cases. Other 19 cases showed scattered or no droplets of lipid. The hyperplastic changes of fascicular tissue were noted in 14 cases. The cells of the outer fasciculata usually contained sudanophilic lipid, frequently with large-sized droplets. Areas of micronodule formation in the zona fasciculata revealed abundant lipid with small or large-sized droplets. However, the nodule with scanty or no lipid was sharply defined in some cases because the abundant lipid in the surrounding compressed cortex. In 8 cases width of the zona reticularis was increased, and sudanophilic lipid was generally small and scanty. One case of adenomas showed evidence of cellular atypism, however, their content of numerous largesized droplets of lipid was similary in both case of primary aldosteronism. Positive grade of the Schultz's reaction often parallel with amount of sudanophilic lipid. Therefore, demonstrable cholesterol and cholesterol esters were present in greatest concentration in the outer fascicular zone. Defined nodules in a hyperplastic cortex and adenomas were characterized by an abundance of Schultz-positive lipid. The surrounding cortex contained comparatively little amount of lipid reacting to the Schultz's reaction. Positive lipid with SmithDietrich's stain exists generally in zona fasciculata and less often in the zona reticularis. In some cases lipoid droplets were noted abundantly in the zona reticularis. The zona glomerulosa has usually little positive lipoid. The cells forming the adenoma differed from those of a surrounding lipoid-rich cortex in lipoid content. The fuchsinophilic materials with ponceau-fuchsin stain were noted in the cases of nodular hyperplasia, especially in the inner cortex. In frozen and carbowax sections, the positive materials were found diffusely distributed intracellularly. With the neotetrazorium salt reaction, a fairly constant quantity of fine reddish granules was noted in each layer of hyperplastic cortex. Cells of the adnoma were negative with this reaction while the surrounding cortex contained fine granules.

\section{Discussion}

Many cases of hypertensive patients were characterized with various degrees of the hyperplastic changes in the adrenal cortex. Major histochemical findings in each layer will be summerized as follows: On the zona glomerulosa; An increase in width of the zona glomerulosa was associated with scattered distribution or absent of sudanophilic droplets. On the contrary, a few cases of hyperplastic zona glomerulosa contained abundant lipid with small to middlesized droplets. With the Schultz's reaction, positive areas in the zona glomerulosa were similar to the sudan III stain. Little or no lipoid was demonstrated with Smith-Dietrich's stain. Neotetrazorium salt reaction showed considerable amount of positive granules in the zona glomerulosa. On the zona fasciculata; The fascicular zone in hyperplastic cortex showed fairly diffuse distribution of sudanophilic materials, especially in the outer fasciculata. The size of lipid droplest was fine except a few cases which contained middle or large sized droplets. With the Simth-Dietrich's stain the intensity and location of positive areas was proportional to the result of sudan III stain. Although the fuchsi- 

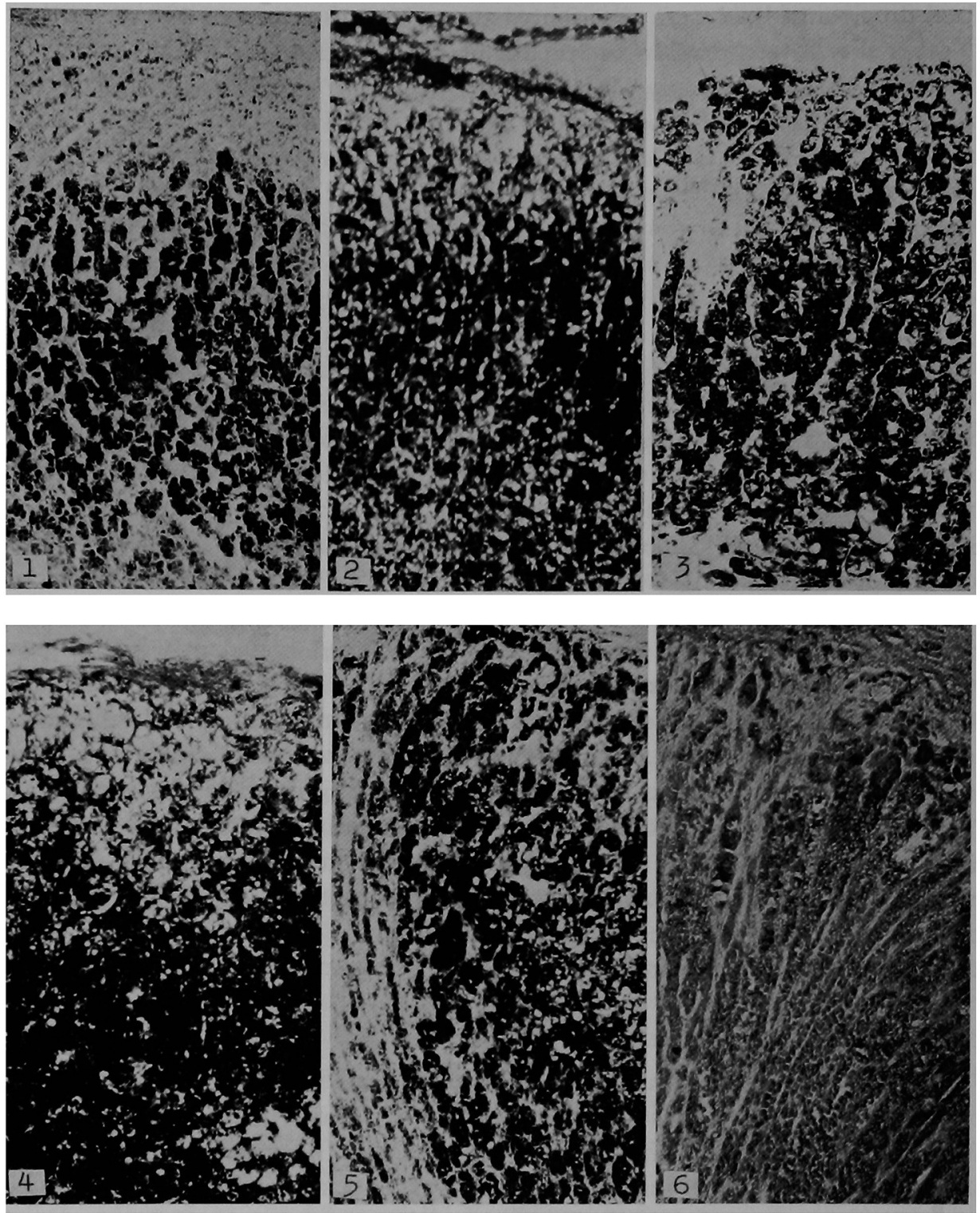

nophilic materials in the hyperplastic fasciculata were generally negative, the extranodular areas in the inner cortex revealed marked positive granules. The origin of cortical zone could not be determined in these inner portion because no sharp transition between the zona fasciculata and zona reticularis was present. The cells of zona faciculata, particularly in the outer portion appeared fine red with neoterazorium salt reaction. On the zona reticularis; In sections with sudan III hyperplastic zona reticularis contained small and granular lipid droplets. Schultz's reaction and Smith-Dietrich's stain were also similar. Positive fashion to ponceau-fuchsin stain in the zona reticularis was seen in the nodular hyperplastic cortex. On the adenoma; The lipids in the adenoma 

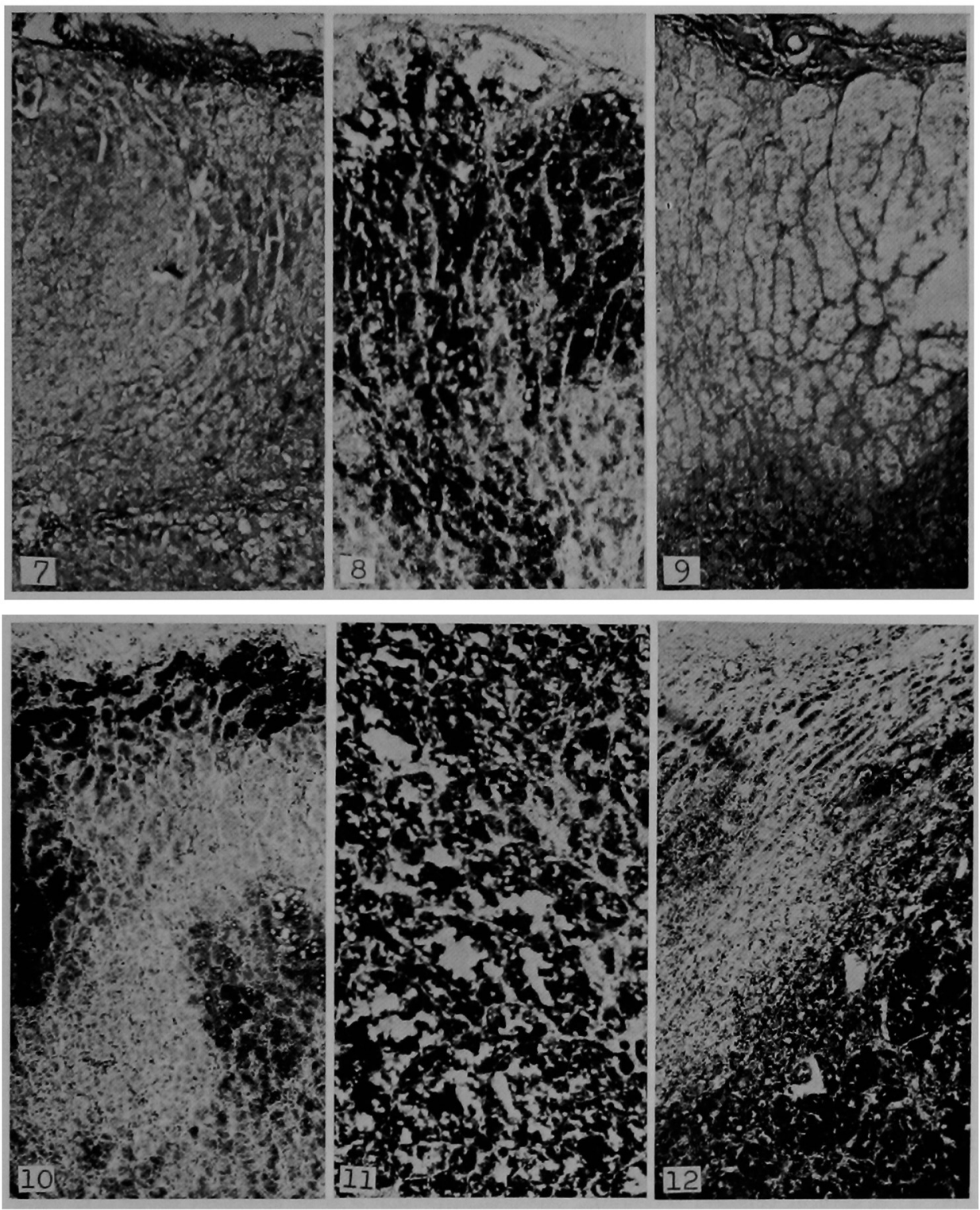

differed quantitatively and qualitatively from those in the extranodular tissue. Both case of the adenomas was characterized with prominent distribution of large-sized sudanophilic lipids. Conglomerate lipid droplets were often fused to fill the cytoplasm. Schultz's reaction showed strongly positive accumulation of cholesterol and cholesterol esters limited to the adenoma. On the contrary, ponceau-fuchsin stain and neotetrazorium salt reaction were generally negative. In extranodular cortex an increase in the width of each layer was noted. No or scanty sudanophilic lipid was found in the zona glomerulosa and fasciculata. These findings seemed to suggest that hyperactivity of the adenomatous cortex may depend on the morphological changes of extranodular tissue rather than 
the adenoma itself.

As for the cases of arteriosclerosis associated with hypertension, some author observed generally on large amount of lipids and ketosteroid as middle to large-sized particles. ${ }^{2)}$ While other observation in the cardiac disease not accompanying hypertension or arteriosclerosis showed rather small amount lipid. ${ }^{8}$ In the contracted kidnely, many reports indicated generally largre quantity of adrenal cortical lipids. ${ }^{4,6}$ ) At present study no fundamental difference in histochemical findings of the adrenal cortex was noted on the severe renal disease and the cases of essential hypertension.

\section{Summary}

Adrenal cortex obtained from 32 autopsy cases associated with hypertension were examined histochemically. Distributive changes of various lipids in each layer were discussed on the nodular or diffuse hyperplasia and the adenoma of cortex.

\section{References}

1) Cohen, R. B., Chapman, W. B. and Castleman, B. : Amer. J. Path., $35: 537,1959.2$ 2) Dietrich, A. und Siegmund, H. : Hb. d. spez. Path. Anat. u. Histol. (Henke-Lubarsch) VIII, 192e. 3) Fukushima, H. : Nissin Igaku $44: 48,1957.4$ 4) Nishinoiri, M.: The Journal of the Chosen Medical Association $24: 167,1934 . \quad 5)$ Pearse, A. G. E. : Histochemistry, Theoretical and Applied. Little, Brown and Co., Boston, $1953 . \quad 6)$ Rogers, W. F. and Williams, R. H. : Arch. Path., $46: 451,1948 . \quad 7)$ Sasano, N. : Acta Path. Jap., $10: 395$, 1960. 8) Shimamoto, H. : Acta Med. Univ. Kioto $38: 1,1955 . \quad 9)$ Zinsser, A. D. and Zinsser, H. H. : Arch. Path., 51 : 393, 1951.

\section{Explanation of Plates}

Fig. 1 A case of nephrosclerosis. No sudanophilic lipid in the zona glomerulosa with an incrase in width is found. Sudan III stain.

Fig. 2 The same case as Fig. 1. Abundant lipoid is seen in the zona fasciculata, and moderately present in the zona reticularis. Smith-Dietrich's stain.

Fig. 3 A case of subarachinoidal hemorrhage. A remarkable increase of lipids in the hyperplastic cortical zones is found. Sudan III stain.

Fig. 4 The same case as Fig. 3. No lipoid distribution in the outer cortex is noticed. Smith-Dietrich's stain.

Fig. 5 A case of cerebral softening. Nodular hyperplasia with abundant droplets of sudanophilic lipid is found in the Zona fasciculata. Sudan III stain.

Fig. 6 The same case as Fig. 5. Positive granules are diffusely distributed in the nodular hyperplasia of the cortex. Neotetrazorium salt reaction.

Fig. 7 A case of cerebral hemorrhage. Reactive areas for ketosteroidprotein complex are shown in extranodular cortex. Ponceaufuchsin stain.

Fig. 8 A case of myocardial infarction. Relatively abundant droplets of sudanophilic lipid in the outer cortex and the zona reticularis with scanty presence of lipid are noted. Sudan III stain.

Fig. 9 The same case as Fig. 8. Reactive areas with ponceau-fuchsin stain are limited to the zona reticularis. Ponceau-fuchsin stain.

Fig. $10 \mathrm{~A}$ case of cerebral softening and nephrosclerosis. An increase of lipid in the zona glomerulosa and spot-like distribution of lipid in the zona fasciculata are found. Sudan III stain. 
Fig. 11 A case of primary aldosteronism. Adenoma is characterized with numerous largesized droplets of sudanophilic lipid. Sudan III stain.

Fig. 12 The same case as Fig. 11. An increase in width of the extranodular tissue (left half area) with small amounts of lipid is noted. Sudan III stain.

\title{
Histochemical Observations on Several Enzyme Activities in Organs of the Diabetic Rabbit
}

\author{
Nobuo IHARA \\ Department of Pathology, Kyoto University School of Medicine \\ (Prof. Kōzō OKAMOTO)
}

To induce a diabetic condition experimentally, hybrid white rabbits were injected intravenously with $100 \mathrm{mg} / \mathrm{kg}$ of alloxan monohydrate (in a aqueous solution,) $100 \mathrm{mg} / \mathrm{kg}$ of dithizone (in an aqueous ammoniac solution) or $30 \mathrm{mg} / \mathrm{kg}$ of 8-hydroxyquinaldine (in a solution acidified by dilute hydrochloric acid), respectively. Animals were killed by air embolism before the occurence of diabetic condition, or after the various duration of diabetic condition. The liver, the kidney, the heart-muscle, the diaphragm-muscle, the thigh-muscle, the small intestine, the pancreas and the adrenal gland were applied to enzymatic histochemical observations. The techniques used were as follows :

a) Glucose-6-phosphate dehydrogenase (G-6-PD) by the method of Nachlas, Walker and Seligman.

b) Diphosphopyridine nucleotide diaphorase (DPND) and lactic dehydrogenase by the method of Nachlas, Walker and Seligman.

c) Succinic dehydrogenase (SD) by the method of Wachstein and Meisel (NT as a $\mathrm{H}$-acceptor) or Nachlas et al. (Nitro-BT as a H-acceptor).

d) Glucose-6-phosphatase (G-6-Pase) by the method of Wachstein and Meisel.

e) Adenosine triphosphatase (ATP ase) by the method of Padykula and Herman.

f) Acid phosphatase (ACP ase) by the method of Takamatsu.

g) Alkaline phosphatase (ALP ase) by Gomori's modification of the method of his own.

h) Non-specific esterase by the method of Gomori.

i) Phosphorylase (Ph-rylase) by the method of Takeuchi and Kuriaki.

(I) On the activities of G-6-PD, LD, SD, G-6-Pase, ATPase and ACPase in the pancreatic islet cells at the various passage of time (from $15 \mathrm{~min}$. up to $24 \mathrm{hrs}$.) after administration of the reagents, it was found that:

a) After the administration of alloxan, the first of all and significant 